Vol. VII, Fase. 1 e 2, p. $151-160$.

\title{
TECNICA PARA EL ESTUDIO DE LAS DIATOMEAS
}

\author{
F. C. Müller-Melchers \\ $y$
}

Hugo J. Ferrando

El estudio detallado de la estrutura de las Diatomeas exige al observador, estar en posesión de los mejores medios para poder definir claramente, los menores detalles estructurales del frústulo siliceo, base para el estudio taxonómico de estos fito-organismos.

Como es lógico suponer, las Diatomeas no se extraen en estado de pureza al hacer las recolecciones de fitoplancton; ellas vienen acompañadas por otros organismos o restos de diversas estructuras, que en conjunto, dificultan la observación correcta.

Por lo tanto, se hace necesario efectuar una limpieza del material a estudiar, eliminando todo aquello que obstruye la visión nítida. Una vez efectuada esta limpieza, que comporta medios mecánicos y químicos, se procede al montaje en láminas porta-objetos, utilizando para tal fin, medios cuyo poder de refringencia y condiciones de inalterabilidad, permiten obtener preparaciones micrográficas nítidas y estables para las colecciones permanentes.

\section{FIJACIÓN DEL MATERIAL}

Para obtener la fijación de las estructuras con el mayor estado de fidelidad para su identificación posterior, utilizamos la formalina o formol puro (solución acuosa al $40 \%$, que se expende en el comercio). Dado que estas técnicas no persiguen el estudio de las finas estructuras citoplasmáticas y nucleares de las Diatomeas, sino que tienden a estudiar en particular, los detalles de ornamentación del frústulo, consideramos innesesario el uso de fijadores especiales, que no tendrían objeto para el fin que nos ocupa.

La utilidad de esta fijación formolada, es la de mantener los materiales a tratar, fuera de la putrefacción a que se verían afectados, si no se les hiciera tratamiento preservador alguno.

Esta operación se efectúa en el momento en que se recoge el material de la red de fitoplancton, es decir, una vez que se ha trassasado al reci- 
piente que va a contener la muestra definitivamente. La cantidad de formol necesaria para la correcta fijación del material se puede calcular de una manera prática; en efecto, se agregan unas gotas del fijador hasta que la muestra expida un ligero olor, característico de la formalina.

Este método de dosificación, a pesar de parecer a primera vista, un tanto rudimentario, tiene la ventaja de su practicidad, pues debemos tener en cuenta que estas manipulaciones se deben efectuar en plena campaña de recolección, donde los recursos de laboratorio son muy limitados. $Y$ por último, reforzando estas consideraciones, diremos que, mediante este simple $\mathrm{y}$ económico procedimiento, tenemos en el presente infinidad de muestras de plancton total, recolectadas años atrás y que no presentan ningún signo de descomposición.

\section{LIMPIEZA DEL MATERIAL}

Según el material a mano se procede a la limpieza. Las muestras planctónicas ya fijadas, deben lavarse con seis (6) cambios de agua utilizando la centrífuga, recomendándose para los cuatro (4) últimos lavados el uso de agua destilada. Las centrífugas utilizadas para este cometido pueden ser las pequeñas $\mathbf{y}$ prácticas accionadas a mano, con dos tubos de $15 \mathrm{cc}$ y con pinza para fijarlas a la mesa, cuando el laboratorio no disponga de corriente elétrica apropriada; o por el contrario cuando las circunstancias lo permiten, utilizar las centrífugas eléctricas empleando tubos cónicos de 15cc. El regimen de velocidad apropriado es el de unas 2000 a 2500 revoluciones por minuto, durante unos cinco (5) minutos para cada cambio de agua.

Cuando se está en presencia de materiales constituídos por rocas o material de fondo, se efectúa un lavado previo utilizando un tamiz de tela de bronze, para evitar los detritos y la arena. Como el material de fondo puede contener restos de moluscos, se hierve con ácido clorhídrico comercial hasta que no se produce más efervescencia. El resto se lava en centrífuga haciendo $\operatorname{los} 6$ cambios de agua mencionados. Si contiene arena, ésta se elimina por decantación, utilizando un tubo de ensayo de buen tamaño.

Todos estos procedimientos tienen a eliminar las sales de calcio, que en el curso del posterior cocimiento con ácido sulfúrico comercial $\left(66 .^{\circ}\right.$ Bé), puenden originar cristales de sulfato de calcio, yeso, que son insolubles y que estorbarán la observación posterior al microscopio.

Las formas grandes y robustas del plancton, como Coscinodiscus, Actinocyclus, Actinoptychus, Pleurosigma, Nitzschia, Navicula, etc. requieren otra limpieza o procedimiento.

Se procede a la destrucción de la matéria orgánica incluída en los frústulos y al mismo tiempo también, se abren o separan las "cajitas" * de

* Expresión proveniente del término "cajita de polvos" con que se comparan las dos valvas encajadas entre sí. 
que están compuestas las Diatomeas, facilitando de este modo la investigación por ambos lados de las valvas.

Procedimiento rápido o cruento - Se cubre el material, colocado previamente en una cápsula de porcelana, con ácido sulfúrico concentrado comercial $\left(66^{\circ} \mathrm{Bé}\right)$. Este procedimiento se tiene que hacer bajo campana, pues se producen gases tóxicos. El color del material así tratado, se torna negro, después de hervir durante veinte (20) minutos, utilizando una llama moderada del mechero Bunsen. Al cabo de este tiempo, se agrega mediante una pipeta larga (de ser posible, unos 40 ó más centímetros), ácido nítrico en pequeñas cantidades y por los bordes de la cápsula, hasta que se produzca la decoloración del material, pasando del tono negro primitivo, gradualmente, hasta la decoloración completa. En esta operación hay que tomar precauciones, puesto que al agregar el ácido nítrico generalmente se producen proyecciones del líquido contenido en la cápsula. Se retira la llama del mechero y se deja enfriar existiendo un procedimiento clásico para evitar la produción de reacciones violentas en la mezcla agua-ácido y al mismo tiempo para acelerar el proceso de lavado del ácido que se utilizó. Se procede de la siguiente manera: - se vierte el contenido de la cápsula (material con ácido, una vez que hubo enfriado) en un recipiente de vidrio que contiene agua hirviendo. De este modo se asientan con más facilidad las diatomeas que si se trabaja con ácido concentrado. A los efectos de una mayor eliminación del ácido, antes de la centrifugación, es conveniente efectuar dos o tres veces el procedimiento indicado, dejando asentar el material $y$ eliminando el ácido sobrenadante antes de repetir nuevamente la operación. Procediendo de este modo, al llegar a las centrifugaciones finales, solamente se halla el ácido en vestigios y por lo tanto se facilita su eliminación total. Luego se pasa el contenido de la cápsula a los tubos de centrífuga y se procede a efetuar los seis lavados arriba indicados.

Procedimiento lento - Para una oxidación más suave se emplea el permanganato de potasio en solución al $10 \%$.

En primer término se deja asentar el material en uno tubo de ensayo y una vez producida la decantación, se elimina el líquido sobrenadante; se cubre el material con permanganato de potasio al $10 \%$ y después de agitar el tubo, a fim de que se mezcle bien el oxidante con el material, se deja en reposo, en un lugar más bien cálido (nunca utilizar la ebullición), durante 24 horas. Una vez transcurrido ese tiempo se vierte el contenido del tubo en una cápsula de porcelana, acidulando el medio con unas pocas gotas de ácido sulfúrico, para luego cubrir el material con agua oxigenada de 10 volúmenes o Perhydrol; es recomendable efectuar este procedimiento al abrigo de la campana de protección. Finalmente, lavar como se ha indicado anteriormente.

Con este método se produce oxígeno en estado naciente, que oxida la mayor parte de la materia orgánica. Se puede graduar la intensidad de la oxidación, utilizando mayor o menor cantidad de permanganato de potasio (variando la concentración de la solución); es decir, que de acuerdo al material, se puede producir una débil o una fuerte oxidación. 
Tdos los procedimientos apuntados, cualquiera sea su tipo, deben tener como condición primordial, la máxima prolijidad en cuanto a limpieza se refiere. En especial hay que poner atención a los lavados sucesivos del material, los tres ultimos de ellos por lo menos, deben hacerse con agua destilada. Hay que considerar que cuanto mejor lavado esté un material, mejores serán las preparaciones que de él se obtengan.

A los efectos de la conservación posterior del material de estudio obtenido, es imprescindible hacerle un tratamiento de preservación apropriado. Para ello se le agrega unas gotas de formol, o se utiliza alcohol a $\mathbf{7 0} \%$ en el último lavado, en vez de utilizar agua destilada como se indicó. Esta precaución es importante a tener en cuenta, pues de ese modo se elimina la posible producción de hongos filamentosos. El uso del formol o en su defecto el alcohol a $70 \%$, depende del destino posterior a darle al material. Para estudios generales, el formol es el indicado; pero cuando se realice el estudio de las finas estructuras (microscopía eletrónica) es conveniente el uso del alcohol a $70 \%$ que las preserva sin destruirlas.

\section{MATERIALES ESPECIALES}

Contenidos estomacales de peces, crustáceos, holoturias u otros animales marinos, se "cuecen" primeramente con ácido clorhídrico para eliminar las sales de calcio; luego, con ácido nítrico, para eliminar la materia orgánica y si todavía ésta llega a subsistir, se procede con ácido sulfúrico. Debemos destacar que es necesario realizar prolijos lavados con agua destilada entre las operaciones mencionadas.

Material de guano - Se hace hervir dos veces, con ácido nítrico, para eilminar la urea y al mismo tiempo una especie de cemento que suele pegar las Diatomeas en un conjunto. Si aún con este procedimiento no se despegan, hay que recurrir al empleo de la soda caústica al $1 \%$.

Se procede de la siguiente manera: se coloca el guano después de tratarlo con ácido nítrico y habiendo sufrido un buen lavado en centrífuga con agua destilada, en un tubo de reacción y se cubre con la solución de soda cáustica fría. El tubo se lleva al baño maría, ultilizando para ello un jarro esmaltado de uso corriente en el laboratorio conteniendo agua fría, en cuyo seno se coloca el tubo; se calienta el conjunto hasta que el agua del jarro entra en ebullición, en este momento se retira del fuego y se vierte en agua fría el contenido del tubo, para evitar la acción prolongada de la soda cáustica. Se observa bajo microscopio, si se desligaron los frústulos; en caso contrario, se repite el procedimiento.

Material fósil - Previamente se desmenuza la roca de diatomita en pequeños trozos (llevándolos al tamaño de arvejas); el material se coloca en un jarro enlozado $y$ se le agrega hiposulfito de sodio (tiosufato) cristalizado o sulfato de sodio cristalizado. Se funde el conjunto al calor de la llama del mechero, hasta que los cristales desprenden su agua de cristalización; se deja enfriar antes de hacer el lavado. Se produce 
la seguiente acción: el agua de cristalización penetra en los orificios y hendiduras del material, $y$ al cristalizar en el seno del mismo, produce el desmenuzamiento de la roca de diatomita por dilatación. Se procede dos o tres veces de esta manera hasta que el material queda reducido a su mínima expresión.

Posteriormente se lava y se trata con ácido clorhídrico para evitar las sales de calcio. Se lava nuevamente.

Revisar luego al microscopio, para el caso en que todavía quede adherido cemento; siendo así se procede con soda cáustica al $1 \%$ como en el caso del guano. Si aún falta limpiar, se efectúa un hervor con ácido sulfúrico y un lavado posteriór con agua destilada.

Recalcamos nuevamente, que es fundamental el tratamiento por ácido clorhídrico y el lavado con agua destilada, efectuado de una manera minuciosa.

\section{MONTAJE DE LAS PREPARACIONES}

El primer punto a tratar en este problema es la utilización de un medio apropriado para incluir las Diatomeas. Existen varios, de utilización corriente en las técnicas micrográficas; a continuación damos una lista de algunos de ellos con sus respectivos índices de refracción:

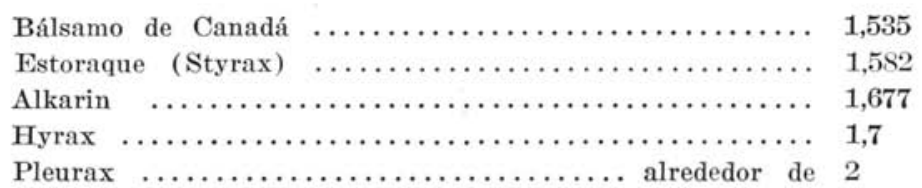

Según el espesor que se quiere conseguir, conviene usar un medio de mayor o menor poder refractivo. Esto quiere decir, un medio - bálsamo, resina natural o artificial - que produzca una imagen de la Diatomea $\mathbf{y}$ de sus esculturaciones - perlas, rayos, líneas, estrías, etc., que son a veces tan finas y además por su cercanía entre ellas, que hacen sumamente engorroso su estudio detallado.

En la determinación de las diferentes especies y formas, su apreciación se basa en el largo y ancho, así como en la estriación que presentan las Diatomeas. En este procedimiento se usa como standard la medida seguiente: - tantas estrías, perlas, rayas, hexágonos, etc. en 0,01 $\mathrm{mm}$.

Se compreende que es necesario disponer para este trabajo de un medio de inclusión que permita la mayor claridad en el campo microscópico.

Como medio de buena calidad, se ha encontrado el "Alkarin" que reune una refracción elevada y un manejo sumamente fácil. Este producto se expende en el comercio bajo ese nombre y su fabricante es: Chroma-Gesellschaft, Schmid \& Co., Stgt. - Untertürkheim, Hindelangerstr. 19, West-Deutschland. 


\section{Instrumentos necesarios}

- Lámpara de alcohol con llama pequeña e mechero Bunsen con veladora.

- Banco de secamiento (Chapa de cobre). Para plancton muy delicado como lo es el que contiene Chaetoceros y cadenas de Thalassiosira, se utiliza una cocinita elétrica con un trozo de chapa de plata, niquelina o acero inoxidable.

- Pinza de presión constante para porta-objetos.

- Aguja de Histología con mango.

- Barras de vidrio fino.

- Porta-objetos bien limpios $y$ desengrasados.

- Cubre-objetos en iguales condiciones de limpieza, usando de preferencia la medida $18 \times 18 \mathrm{~mm}$ ó $15 \times 15 \mathrm{~mm}$, cuadrados o circulares. Los circulares de $15 \mathrm{~mm}$ de diametro se prestan de especial manera, puesto que en el caso de medidas mayores como $20 \times 20$ ó más, la vista se cansa fàcilmente si se investiga con platina móvil.

\section{Manipulaciones preliminares}

El material, que se encuentra en agua destilada, se agita para evitar que se formen flóculos. Se toma un cubre-objetos de $15 \mathrm{~mm}$ de diámetro, que esté bien limpio, por medio de una pinza y se coloca, sin tocar la superficie de la laminilla con los dedos (evitar rastros de grasa), sobre un porta-objetos.

Con una pipeta tipo Pasteur, se colocan unas gotas de agua destilada, tratando de que cubran completamente la lámina llegando hasta los bordes de la misma, esto se facilita expeliendo aliento sobre la preparación.

Del frasco que contiene la muestra, se extrae una pequeña cantidad de material, utilizando una pipeta limpia y se dejan caer una o dos gotas (según la riqueza de la muestra) en el centro del cubre. Si este material no se esparce adecuadamente, se toma una pipeta larga y fina, provocándose con ella la remoción de la mezcla, mediante la proyección de aire por medio de la pipeta. Hay que cuidar en esta operación que el líquido no salga de la lámina cubre-objetos y se introduzca entre ésta $\mathbf{y}$ el porta; ayuda en este sentido la tensión superficial del líquido, por lo tanto el cuidado a tener, es el de no vencer esa tensión superficial.

Se pueden preparar así, 3 ó 4 portas con sus respectivos cubres, y hacer la siguiente operación de secamiento e incineración con varias muestras al mismo tiempo.

\section{Secamiento o incineración}

En esta operación utilizamos el banco de secamiento, el cual se puede construir fàcilmente con un soporte de hierro de los empleados en el laboratorio para el uso de embudos. En efecto, se coloca sobre el anillo la platina de cobre que soportará las láminas. Este sistema tiene la ventaja de poder regular la distancia de la llama al material. Un sustituto de este sistema puede ser la platina caliente de Malassez, de uso corriente en las técnicas histológicas, pero con ella no se puede regular la citada distancia. 
Las láminas a desecar se colocan, una al lado de otra, sobre la platina de cobre, debajo de la cual se halla la lámpara de alcohol con su pequeña llama (de una altura de $1 / 2$ centímetro). En caso de usar el mechero Bunsen se utiliza la llama veladora del mismo; pero recomendamos que en lo posible se emplee la lámpara de alcohol, que rinde mejores resultados que el Bunsen, el cual está sujeto a las variaciones de la presión del gas de las cañerías y exigen una vigilancia constante del processo, para evitar los aumentos de la intensidad del calor.

Observando este processo, se aprecia primero una evaporación ael líquido para después tomar el aspecto de una calcinación, con el característico color blanco grisáceo, que indica que está terminada la operación. La distancia a colocar la llama de la platina, no se puede indicar de una manera exacta, pues como se comprende depende de varios factores (espesor de la chapa, calidad de la llama, etc.); por lo tanto esa distancia queda condicionada a la observación personal del operador.

\section{Preparación de las láminas definitivas}

Se prepara, mientras dura el processo anterior, la cantidad necesaria de portas - bien desengrasados y limpios - , los que luego de secados con un paño limpio, se pasan por la llama para evitar la humedad.

Se toma la solución de Alkarin, que debe tener una fluidez similar a la miel líquida. El Alkarin, que es una resina que se ofrece al comercio bajo forma de pequeñas trozos, se disuelve en Xylol, Benzol o Toluol. De esta disolución, se toman 2 o 3 gotas mediante la barrita de vidrio, y se colocan en el centro del porta-objetos.

\section{Montaje propiamente dicho}

El cubre conteniendo el material (aparentemente reducido a cenizas) se prensa con la pinza de Debrandt, tomando las precauciones con respecto al lado en que se encuentra el material; para ello es conveniente orientarse por el orificio que presenta dicha pinza y acostumbrarse a utilizar el siguiente método: material hacia arriba, al igual, que el orificio de la pinza de Debrandt.

Previamente se pasa la lámina cubre-objetos por sobre la llama para eliminar la humedad del ambiente, e inmediatamente se coloca (material hacia abajo), sobre el Alkarin depositado con anterioridade en el portaobjetos, cuidando que quede bien en el centro del mismo. Todo el conjunto se calienta a la llama directa, hasta que se produzcan burbujas entre las dos láminas, momento en que se retira del calor para, una vez apoyada la lámina, se hace presión suavemente con la aguja histológica aplicada sobre el cubre, hasta conseguir la eliminación total de las burbujas de aire.

Si la cantidad de Alkarin es mayor de la necesaria, éste sobrepasará los límites del cubre, no existiendo problemas al respecto, pues una vez que 
la sustancia se haya desecado, se puede eliminar fácilmente ese exceso mediante un cuchillito bien afilado. En el caso de que falte Alkarin bajo e cubre, se agrega una gota por el borde, la que entra bajo el mismo por capilaridad y luego se pasa nuevamente por la llama de la lámpara de alcohol, repitiendo la operación antes descripta, hasta la desaparición de las burbujas de aire. Se deja enfriar y la preparación está concluída.

Estas preparaciones todavía no están endurecidas, puesto que el $\mathrm{Al}$ karin demora en secarse algunas horas; para acelerar el processo es conveniente a la llama bien pequeña, utilizando para ello el banco antes citado, pero colocando la llama más lejos, para que su acción sea la de suministrar un calor moderado acelerando la evaporación del disolvente (Xylol, Benzol, etc.); para ello, se levanta la chapa de cobre del banco, accionando el anillo que la soporta, para que quede alejada de la llama a una distancia de unos $20 \mathrm{~cm}$.

En todo caso en que se hagan preparaciones de materiales diferentes es indispensable usar nuevas pipetas, para de ese modo estar seguro el operador, de que no incurre en la "contaminación" de la muestra a estudiar-se. Es muy fácil infectar el material en que se trabaja, con otro, usando la misma pipeta para varias muestras; por lo tanto es recomendable hacer uso de una pipeta (tipo Pasteur, de uso en bacteriologia) para cada muestra que se manipula.

En caso de que no se disponga del número apropriado de pipetas, se puede obviar en algo ese inconveniente, teniendo la precaución de lavar inmediatamente las pipetas después de haber entrado en contacto con la muestra; nunca dejar que se sequen sin el lavado previo, puesto que las Diatomeas se pegan muy fácilmente al vidrio. Con esta operación se evita el falseamiento de los resultados, cuando se desean hacer investigaciones corretas de determinaciones de los distintos ejemplares en diferentes estaciones.

Otra solución para cuando se carece de la cantidad apropriada de pipetas es la siguiente: tal como aparece en la figura adjunta, se emplea una sola pipeta, pero con puntas intercambiables, mediante la conexión de un tubo de goma.

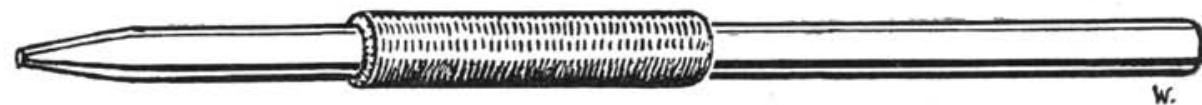

Pipeta con puntas intercambiales (según Müller-Melchers)

$\begin{array}{ccc}\begin{array}{c}\text { Punta } \\ \text { Cambiable }\end{array} & \text { Tubo de } & \text { Tubo de vidrio } \\ \text { (uso permanente) }\end{array}$

Las preparaciones se guardan cara abajo, para que las Diatomeas que todavía no están asentadas definitivmente, se aproximen lo más posible al cubre-objetos, facilitando de este modo el uso de lentes de immersión. 


\section{MONTAJE DE UNA PREPARACION AL AIRE \\ ( Sin medio de inclusión)}

Se utiliza un porta-objetos común, y con pintura laca de color negro se hace un cuadrado de $17 \times 17 \mathrm{~mm}$ (para los cubres $18 \times 18 \mathrm{~mm}$ ) con un pincel fino (pelo de marta); para facilitar ese dibujo de la cámara o celda, se hace una guía de cartulina con la medida indicada (17 $\mathrm{x}$ 17) y se coloca encima del porta-objetos, sosteniéndose el cuadrado bien centrado mediante dos diagonales.

Esta laca se deja secar casi totalmente (se puede apreciar con el dedo), siendo recomendable dejarla secar por demás, pues con el calor de la llama de la lámpara de alcohol siempre es posible ablandarla. Se deben tomar precauciones para evitar la humedad ambiente que puede quedar en el interior del recuadro o celda y luego, con el tiempo perjudicar la preparación; por esa razón se colocarán los portas con la celda ya confeccionada en un desecador (conteniendo cloruro de calcio), hasta el momento de su uso.

El cubre que contiene el material - llevado cara arriba - pasarlo por la llama de la lámpara de alcohol, antes de colocarlo sobre la celda. El calentamiento debe ser suficiente para que elimine totalmente todo resto de humedad de la preparación.

Inmediatamente se coloca sobre la celda de laca, evitando que en esta manipulación la laca se introduzca en la preparación. Como el cubre, por la operación de eliminación de humedad recientemente hecha conserva aún calor, éste es suficiente para ablandar la laca y perimitir un buen cierre de la cámara, el que se ayuda ejecutando ligeras presiones con la aguja de histología. En todo caso, cuando la laca no esté en las condiciones requeridas, se puede efectuar una rápida pasada por la llama para ablandar un poco esa celda.

Se deja secar y enfriar, para cuando se llega a una consistencia firme, se procede con el pincel fino a cerrar definitivamente la celda, utilizando la misma laca negra. Una vez que ha secado esta nueva aplicación, la preparación queda pronta para el estudio de su contenido.

Preparaciones asi realizadas, demuestran una gran cantidad de detalles que, mismo en los medios de incluir, se pierden, especialmente en las especies transparentes del plankton como los Chactoceros, los hilos de las Thalassiosira, etc.

\section{S U M A R I O}

O presente trabalho foi apresentado à IV Reunião do Grupo de Trabalho de Ciências do Mar, reunido em Montevideo (22 a 24 de maio de 1957) sob o patrocínio do Centro de Cooperación Científica da UNESCO para a América Latina. Versa 
sôbre técnicas empregadas no estudo das diatomáceas, compreendendo fixação, limpeza e montagem de preparados microscópicos. Contem referências ao tratamento de amostras obtidas do conteúdo estomacal de peixes, crustáceos, equinodermas e outros organismos marinhos, bem como de guano e material fossil.

\section{B I B L I O G R A F I A}

BAKER, J. R., - 1945. Cytological Technique. London.

CUPP, E. E., - 1943. Marine Plankton Diatoms of the West Coast of North America. Bull. Scripps Inst. of Oceanogr., of the Univ. Cal., vol. 5, n. ${ }^{\circ} 1$, p. 1-238, pl. 1-5, La Jolla, California.

- 1943a. The Microscope. The British Journ. Mier. and Photogr. London.

LANGeron, M., - 1949. Précis de Mieroscopie. Paris.

ROMEIS, B., - 1936. Guía-Formulario de Técnica Histológica. Barcelona. 